\title{
Interactive comment on "Seasonal behaviour of tidal damping and residual water level slope in the Yangtze River estuary: identifying the critical position and river discharge for maximum tidal damping" by Huayang Cai et al.
}

Anonymous Referee \#2

Received and published: 29 March 2019

\section{General comments:}

The manuscript examines the importance of river discharge on tidal damping, residual water level slopes and channel convergence in a seasonal scale in the Yangtze estuary. An analytical model for the tide-river dynamics has been used to understand the underlying mechanisms based on the previous works by the same authors and previous reports from spectra analysis of observed data by other researchers. The authors have identified a critical position of maximum tidal damping along the estuary for a given river discharge as wet or dry season. They also have identified a critical

Printer-friendly version

Discussion paper 
value of river discharge at a given location, beyond which the tidal damping is reduced with increasing river discharge. It is contrary to the common assumption that larger river discharge leads to heavier tidal damping, which is driven by the cumulative effect of residual water level and channel convergence. This is the most important new insight of present manuscript to enhance our understanding of the nonlinear tide-river interactions and guide effective water management in the Yangtze estuary and other estuaries although the methods used were presented. The subject is relevant to the journal, the manuscript is well written and structured. The result analysis is thorough and the discussion is well presented. In conclusion, I recommend its publication after minor revision.

\section{Specific comments:}

L55-56: "little effort has been devoted to exploring the effect of river discharge on channel convergence, which is the other control factor for tide-river dynamics": How can the river discharge affect channel convergence? Provide explanations and references.

L105-106: "Datong hydrological station (where the tidal limit is)": As the authors have read reference about the fluctuation of tidal limit in the Yangtze estuary, you should note the significant fluctuation of the tidal limit during the similar period to the present manuscript. And one of the main identification result by the authors is the critical position of tidal damping controlled by the river discharge. Provide some explanations as the tidal limit is directly relevant to the effect of river discharge on the tidal damping and residual water level. In particular, suggest the authors to insert more words of relevant discussion into the section 5 .

L231-234: "a threshold, corresponding to a critical value of river discharge, beyond which the relationship between the tidal damping rate and river discharge switches from negatively to positively correlated": Why the channel geometry is missing for the reason explanation of switch occurred here. Please insert more words into the section 5 of discussion about the correlation of critical value of river discharge with the channel

Printer-friendly version

Discussion paper 
convergence.

Technical corrections:

HESSD

L353: Replace St by Sr.

L357: Insert a blank space between S and a.

Interactive

comment

Interactive comment on Hydrol. Earth Syst. Sci. Discuss., https://doi.org/10.5194/hess-2018524, 2018. 